\title{
PULMONARY ARTERIAL PRESSURE AFTER PRISCOLINE IN MITRAL STENOSIS
}

\author{
BY \\ K. BRAUN, G. IZAK, AND S. Z. ROSENBERG \\ From the Cardiovascular Laboratory and Department of Internal Medicine (Division ' $B$ '), \\ Rothschild-Hadassah University Hospital, Jerusalem, Israel * \\ Received March 2, 1956
}

It has been observed that in certain cases of mitral stenosis the increase in pulmonary arterial pressure is out of proportion to the pressures on the venous side of the pulmonary circulation. This increase is due to narrowing of the pulmonary arterioles (Dexter et al., 1950; Baker et al., 1952; Ferrer et al., 1952), which may result either from organic changes in the pulmonary arterioles (intimal proliferation and medial hypertrophy) (Parker and Weiss, 1936; Larabee et al., 1949) or from increased pulmonary vascular tone due to over-activity of the autonomic nervous system (Holling, 1952; Curti et al., 1953) or both.

Various drugs have been used to determine the influence of the autonomic nervous system on pulmonary hypertension in cases of mitral stenosis. Thus, large decreases in right ventricular pressure (Wilson and Keeley, 1953) and in pulmonary arterial pressure-without decrease in cardiac output-have been observed following the administration of hexamethonium (Davies et al., 1954). Using priscoline Gardiner (1954) observed a fall in the pulmonary arterial pressure in two cases of mitral stenosis.

In the present study priscoline was used to analyse the role played by increased vascular tone. in the pulmonary hypertension of mitral stenosis. Priscoline $\dagger$ (2-benzyl 1-4.5 imidazoline hydrochloride) is a sympathicolytic and adrenolytic agent (Chess and Yonkman, 1940) and is thought to cause vaso-dilatation by blocking the sympathetic end-organs in the vessel walls.

\section{MATERIAL AND METHODS}

Fourteen patients with predominant mitral stenosis, confirmed at operation, and with various degrees of pulmonary hypertension were studied. None was suffering at the time of the examination from acute pulmonary complications such as pneumonia or pulmonary infarction and none had clinical or laboratory signs of rheumatic activity.

Right heart catheterization was performed in the usual manner (Cournand and Ranges, 1941; Bloomfield et al., 1946). Pulmonary arterial and brachial arterial pressures were recorded simultaneously by an electromanometer on a Sanborn polyvisocardiette. Mean pressures were obtained by electrical integration. Mixed venous blood was withdrawn from the pulmonary artery simultaneously with brachial arterial blood. Oxygen content and capacity were determined by the method of Van Slyke and Neill (1924). Oxygen consumption was measured in four patients with a closed

* This study was supported by the P. D. Lown Fund.

$\dagger$ Ciba Pharmaceutical Product, Inc. 
spirometer and in eight patients expired air was collected in a Douglas bag and analysed for oxygen and carbon dioxide with a Scholander micro-gas analyser (Scholander, 1947). Blood pressures were recorded and blood samples were obtained before and 2,10,20, and 30 minutes after the injection of $25 \mathrm{mg}$. of priscoline through the catheter. Cardiac output (Fick principle) and pulmonary vascular resistances (Gorlin et al., 1951) were determined before and at 10 and 30 minutes following the injection. In four additional cases of mitral stenosis only pulmonary wedge pressure and simultaneous brachial arterial pressure were recorded before and 10 minutes after administration of priscoline.

\section{ResulTS}

Priscoline caused in all patients a transient increase in the pulse rate for about five minutes. This increase ranged from 12 to 20 beats a minute.

In two of the fourteen patients (Cases 13 and 14, Table I) examined, the development of pulmonary œdema 5 minutes following the injection of priscoline prevented the completion of the observation. This occurred without any appreciable fall in the pulmonary arterial pressure being recorded.

TABLE I

Summary of Data obtained 10 Minutes after Injection of Priscoline in 14 Patients

\begin{tabular}{|c|c|c|c|c|c|c|c|c|c|}
\hline \multirow{2}{*}{ No. } & \multirow{2}{*}{ Name } & \multicolumn{2}{|c|}{$\begin{array}{l}\text { Pulmonary artery } \\
\text { (mean) } \mathrm{mm} \text {. Hg }\end{array}$} & \multicolumn{2}{|c|}{$\begin{array}{l}\text { Brachial artery } \\
\text { (mean) } \mathrm{mm} . \mathrm{Hg}\end{array}$} & \multicolumn{2}{|c|}{$\begin{array}{l}\text { Pulmonary artery } \\
\mathrm{O}_{2} \text { saturation } \%\end{array}$} & \multicolumn{2}{|c|}{$\begin{array}{l}\text { Brachial artery } \\
\mathrm{O}_{2} \text { saturation } \%\end{array}$} \\
\hline & & $\begin{array}{r}\text { Before } \\
\text { Pr }\end{array}$ & $\begin{array}{l}\text { After } \\
\text { ne }\end{array}$ & $\begin{array}{r}\text { Befor } \\
\mathbf{P}\end{array}$ & After & $\begin{array}{r}\text { Before } \\
\quad P 1\end{array}$ & After & $\begin{array}{r}\text { Befor } \\
P\end{array}$ & $\begin{array}{l}\text { After } \\
\text { ine }\end{array}$ \\
\hline $\begin{array}{r}1 \\
2 \\
3 \\
4 \\
5 \\
6 \\
7 \\
8 \\
9 \\
10 \\
11 \\
12 \\
13 \\
14\end{array}$ & $\begin{array}{l}\text { B. A. } \\
\text { F. B. } \\
\text { S. N. } \\
\text { L. H. } \\
\text { B. N. } \\
\text { C. W. } \\
\text { F. B. } \\
\text { P. B. } \\
\text { R. A. } \\
\text { D. T. } \\
\text { Ch. K. } \\
\text { P. E. } \\
\text { S. D.* } \\
\text { F. R.* }\end{array}$ & $\begin{array}{l}75 \\
60 \\
58 \\
55 \\
37 \cdot 5 \\
37 \cdot 5 \\
27 \\
26 \\
26 \\
25 \\
17 \\
15 \\
40 \\
85\end{array}$ & $\begin{array}{l}39 \\
43 \\
25 \\
40 \\
25 \\
25 \\
15 \\
16 \\
22 \\
18 \\
17 \\
14 \\
36 \\
80\end{array}$ & $\begin{array}{l}87 \\
80 \\
117 \cdot 5 \\
105 \\
100 \\
87 \cdot 5 \\
75 \\
83 \\
80 \\
58 \\
90 \\
77 \\
87 \\
100\end{array}$ & $\begin{array}{r}83 \\
75 \\
110 \\
85 \\
75 \\
63 \\
60 \\
\frac{100}{100} \\
45 \\
65 \\
68 \\
99\end{array}$ & $\begin{array}{l}67 \cdot 5 \\
48 \\
74 \\
65 \\
68 \cdot 5 \\
87 \\
72 \\
\frac{8}{86} \\
68 \\
67 \\
67 \\
55\end{array}$ & $\begin{array}{l}75 \\
60 \\
65 \cdot 5 \\
59 \\
61 \\
88 \\
73 \\
\frac{76 \cdot 5}{72} \\
7 \overline{-} \\
71 \\
60 \cdot 5\end{array}$ & $\begin{array}{c}97 \\
96 \\
102 \\
94 \\
93 \cdot 5 \\
102 \\
93 \cdot 5 \\
\overline{-} \\
100 \\
101 \\
97 \\
94 \\
90\end{array}$ & $\begin{array}{l}91 \\
76 \cdot 5 \\
98 \cdot 5 \\
88 \\
88 \\
95 \\
90 \\
-\overline{96 \cdot 5} \\
92 \cdot 5 \\
91 \\
97 \\
86\end{array}$ \\
\hline
\end{tabular}

* These two patients developed pulmonary adema, and therefore the observation had to be interrupted after 5 minutes.

In 11 out of the 12 remaining patients the pulmonary arterial mean pressure decreased following the administration of priscoline, the fall ranging from 7 per cent to 57 per cent of the initial values. In another patient the pulmonary arterial pressure did not change (Table I). Some correlation was observed between the initial height of the pulmonary arterial pressure and the extent of the decrease in this value following the injection of priscoline. The higher the initial pressure, the greater the fall following administration of the drug (Table I). In Cases 9-12, where the initial pulmonary artery pressure was either normal or only slightly raised the drop in pressure following priscoline was small.* The mean pressure in the brachial artery was measured simultaneously with the pulmonary arterial pressure in 10 of the 12 patients. The brachial arterial pressure decreased in 9 patients, the fall ranging from 6 per cent to 25 per cent of the initial values, and increased in one patient by 2 per cent. The maximal effect on the pulmonary and brachial arterial

* This fall in the pressure may be insignificant, since similar changes are within the range of variations during catheterization. 
pressures was noted 10 minutes following the administration of the drug. The onset of the fall in the pulmonary arterial pressure preceded that in the brachial artery (Fig. 1).

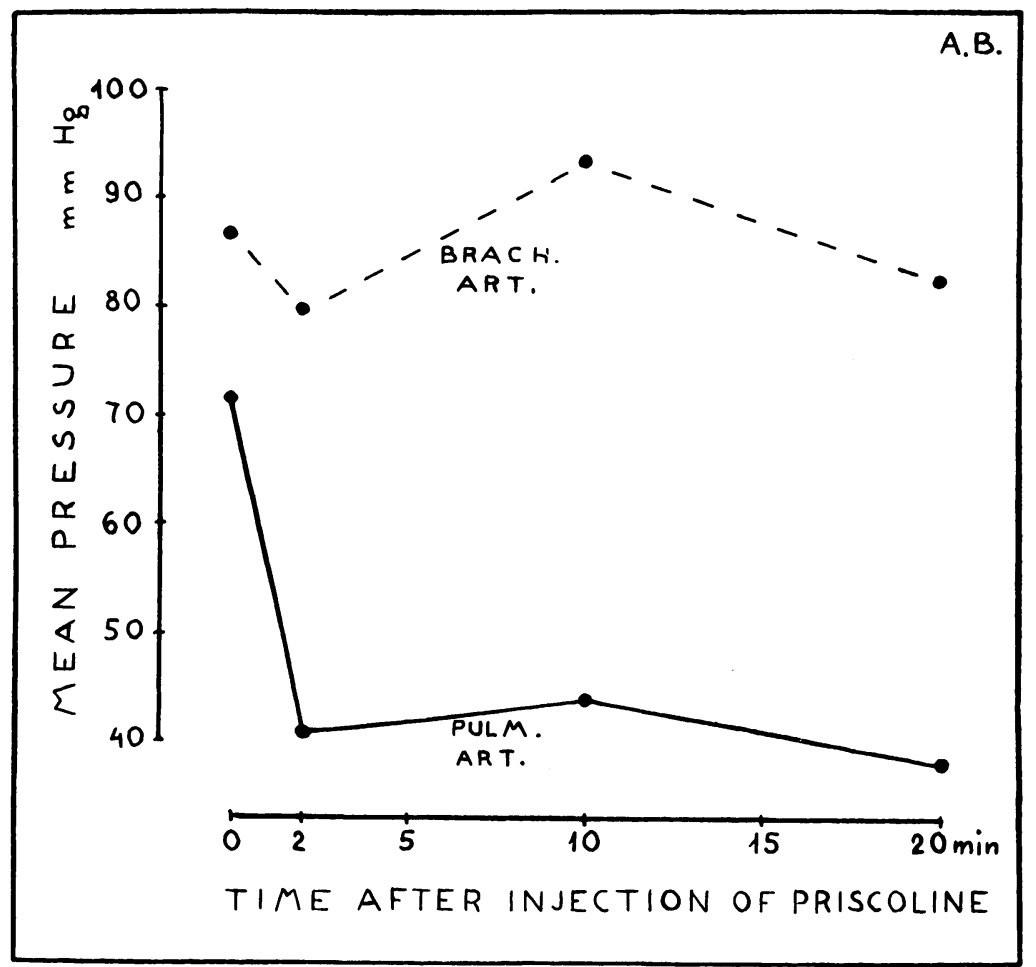

FIG. 1.-Showing the changes in pulmonary arterial pressure and brachial arterial pressure following the injection of $25 \mathrm{mg}$. of priscoline.

The oxygen saturation in the pulmonary arterial blood changed during the course of the observations, falling in five patients by 3.0 to 9.5 per cent, and rising in the other five patients by 1 to 12 per cent. The oxygen saturation in the brachial arterial blood decreased in all ten patients examined, the fall ranging from 3.5 to 19.5 per cent. There was no relation between changes in the oxygen saturation following the injection of priscoline and initial pulmonary arterial and brachial arterial pressures (Table I).

The cardiac output increased in seven patients (from 1.6 to $5.01 . / \mathrm{min}$.), remained unchanged in two, and decreased in another patient from $8.91 . / \mathrm{min}$. to $4.51 . / \mathrm{min}$., following the administration of priscoline. The pulmonary vascular resistance diminished in nine patients, the decrease ranging from 48 to 1025 dyn. cm..$^{-5}$ sec., and increased in one patient by 118 dyn. $\mathrm{cm} . .^{-5} \mathrm{sec}$.

In four patients in whom only pulmonary wedge pressures were measured the mean pressure values were $30,27,25$, and $17 \mathrm{~mm}$. $\mathrm{Hg}$ respectively. There was no great change in these values following the injection of priscoline.

\section{Discussion}

It has been demonstrated above that pulmonary hypertension in mitral stenosis may be reduced by priscoline, a sympathicolytic agent. Furthermore, the greater the initial pulmonary arterial pressure, the larger the decrease following the injection of priscoline. Since the fall in pulmonary arterial pressure preceded that in the systemic artery, the effect of priscoline on the pulmonary arterial pressure was apparently not secondary to pooling of blood in the peripheral circulation. 
Our studies suggest, there fore, that the autonomic nervous system plays an important role in the maintenance of pulmonary hypertension accompanying mitral stenosis, probably by producing increased vasomotor tone in the pulmonary arterioles. These observations confirm those of several other authors who found that priscoline, as well as tetra-ethylammonium-chloride and hexamethonium reduced pulmonary hypertension due to various causes (Davies et al., 1954; Fowler et al., 1950; Dresdale et al., 1954). However, in none of our patients with much pulmonary hypertension did priscoline reduce pulmonary pressure to normal. The residual elevation of the pulmonary arterial pressure may be due to organic changes in the pulmonary vascular tree (Parker and Weiss, 1936; Larabee et al., 1949), to the transmitted back pressure caused by the stenotic valve, or to myocardial insufficiency (Harvey et al., 1949; 1955). The failure of priscoline to lower the pulmonary wedge pressure in four cases suggests that the main effect of the drug is on the tonus of the pulmonary arterioles.

The pulmonary arteriolar spasm found during these observations probably represents an important factor in the causation of the so-called protective pulmonary hypertension which shields the capillaries from an excessive increase in pulmonary blood flow (Wood, 1952). This increase might raise the hydrostatic pressure and eventually lead to the development of pulmonary œdema. However, the pulmonary œdema that appeared in two of our patients after injection of priscoline was apparently not caused by reduction in this protective pulmonary hypertension. In these two cases the pulmonary arterial pressures had not yet fallen appreciably when the œdema developed. The probable cause of this serious complication was the increase in pulse rate after the injection. Since Davies et al. (1954) noted that pulmonary œdema develops more frequently in cases of mitral stenosis with excessive pulmonary hypertension, they reject the concept of protective pulmonary hypertension and recommend hexamethonium as a therapeutic agent in these patients. Our series is too small to draw conclusions as to whether priscoline is beneficial or contra-indicated in this condition.

While the changes in the oxygen saturation of the pulmonary arterial blood were not consistent, the peripheral oxygen saturation fell significantly (from 3.5 to $18.5 \%$ ) in all 10 cases studied. A possible explanation for this is that vasodilation produced by priscoline may increase blood flow in lung segments with poorly ventilated alveoli, thus leading to pulmonary venous unsaturation (Curti et al., 1953; Dresdale et al., 1954; Carrol et al., 1953). Another possibility is that the sudden drop in the pulmonary arterial pressure may change the direction of blood flow in the anastomotic branches connecting the pulmonary and bronchial vascular systems in cases of mitral stenosis (Ferguson et al., 1944). Liebow (1953, 1954) suggested that with an increased shunt between the systemic and pulmonary venous circulation, the valves of the bronchial veins may become incompetent and the blood may flow in either direction according to the development of pressure gradients.

It seems quite probable that the calculated increase in cardiac output, which in some cases was over 4 litres, is incompatible with the degree of mechanical obstruction of the mitral valve found at operation. Rapid changes in the circulatory system during an observation of brief duration may cause large variations in the arterio-venous oxygen difference and oxygen consumption. Therefore the reliability of applying the Fick method in such a case has been questioned (Visscher and Johnson, 1953; Donald et al., 1954). Similarly, the calculated values for vascular resistances in the pulmonary and systemic circulation also appear to be not entirely reliable.

\section{Summary AND CONClUSION}

The effect of priscoline on the pulmonary and brachial arterial pressure and oxygen saturation, on cardiac output and vascular resistances was studied in 14 patients with mitral stenosis. The drug caused a significant fall in pulmonary artery pressure, while the fall in the peripheral arterial pressure was much less pronounced. 
Priscoline through its sympathicolytic and adrenolytic effect apparently diminishes pulmonary arteriolar spasm present in cases of mitral stenosis with pulmonary hypertension.

\section{REFERENCES}

Baker, C., Brock, R. C., Campbell, M., and Wood, P. (1952). Brit. med. J., 1, 1043.

Bloomfield, R. A., Lauson, H. D., Cournand, A., Breed, E. S., and Richards, D. W., Jr. (1946). J. clin. Invest., 25, 659.

Carrol, D., Cohn, J. E., and Riley, R. L. (1953). J. clin. Invest., 32, 510.

Chess, D., and Yonkman, F. F. (1940). Proc. Soc. Exp. Biol. Med., 61, 124.

Cournand, A., and Ranges, H. A. (1941). Proc. Soc. Exp. Biol. Med., 46, 467.

Curti, P. C., Cohen, G., Castleman, B., Friedlich, A. L., and Mayers, G. S. (1953). Circulation, 8, 893.

Davies, L. G., Goodwin, J. F., and Van Leuven, B. D. (1954). Brit. Heart J., 16, 440.

Dexter, L., Dow, J. W., Haynes, F. W., Whittenberger, J. L., Ferris, B. G., and Hellems, H. K. (1950). J. clin. Invest., 29, 602.

Donald, K. W., Bishop, J. M., and Wade, O. L. (1954). J. clin. Invest., 33, 1146.

Dresdale, D. T., Michton, R. J., and Schultz, M. (1954). Bull. New York Acad. Med., 30, 195.

Ferguson, F. C., Kobilak, R. E., and Deitrick, J. E. (1944). Amer. Heart J., 28, 445.

Ferrer, M. I., Harvey, R. N., Cathcart, R. T., Cournard, A., and Richards, D. W., Jr. (1952). Circulation, $6,688$.

Fowler, N. O., Westcott, R. W., Hauerstein, V. D., Scott, R. C., and McGuire, J. (1950). J. clin. Invest., $29,1381$.

Gardiner, J. M. (1954). Australian Ann. Med., 3, 59.

Gorlin, R., Haynes, F. W., Goddale, W. T., Sawyer, C. G., Dow, G. W., and Dexter, L. (1951). Amer. Heart J., 41, 30.

Harvey, R. M., Ferrer, M. I., Cathcart, R. T., Richards, D. W., and Cournard, A. (1949). Amer. J. Med., 7, 439.

- $\frac{7}{531}$, Samet, P., Bader, R. A., Bader, M. E., Cournand, A., and Richards, D. W. (1955). Circulation, 11,

Holling, H. E. (1952). Brit. med. Bull., 8, 358.

Larabee, W. F., Parker, R. L., and Edwards, J. E. (1949). Proc. Staff Meet. Mayo Clin., 24, 316.

Liebow, A. A. (1953). Amer. J. Path., 21, 251.
(1954). Bull. New York Acad. Med., 30, 66.

Parker, F., Jr., and Weiss, S. (1936). Amer.J. Path., 12, 573.

Scholander, P. F. (1947). J. Biol. Chem., 167, 235.

Van Slyke, D. D., and Neill, J. M. (1924). J. Biol. Chem., 61, 524.

Visscher, M. B., and Johnson, J. A. (1955). J. Appl. Phys., 5, 635.

Wilson, V. M., and Keeley, K. J. (1953). South African J. med. Sc., 18, 125.

Wood, P. (1952). Brit. med. Bull., 8, 348. 